\title{
Microwave assisted template synthesis of silver nanoparticles
}

\author{
K J SREERAM*, M NIDHIN and B U NAIR \\ Chemical Laboratory, Central Leather Research Institute, Chennai 600 020, India
}

MS received 16 April 2008; revised 26 May 2008

\begin{abstract}
Easier, less time consuming, green processes, which yield silver nanoparticles of uniform size, shape and morphology are of interest. Various methods for synthesis, such as conventional temperature assisted process, controlled reaction at elevated temperatures, and microwave assisted process have been evaluated for the kind of silver nanoparticles synthesized. Starch has been employed as a template and reducing agent. Electron microscopy, photon correlation spectroscopy and surface plasmon resonance have been employed to characterize the silver nanoparticles synthesized. Compared to conventional methods, microwave assisted synthesis was faster and provided particles with an average particle size of $12 \mathrm{~nm}$. Further, the starch functions as template, preventing the aggregation of silver nanoparticles.
\end{abstract}

Keywords. Silver nanoparticles; surface plasmon resonance; SAED.

\section{Introduction}

Among various nanoparticles which have found commercial applications, the silver nanoparticles find several applications. Considerable interest has been generated by use of silver nanoparticles for deactivating HIV at concentrations with little or no cytotoxicity (Elenchiguerra et al 2005), in surface enhanced Raman scattering (Pal and Pal 1999; Lu et al 2005), plasmonics (Kelly et al 2003), medicine, catalysis, photonics and optics (Evanoff and Chumanov 2005). In the coating industry, silver nanoparticles are employed for spectrally selective coating for solar energy. Owing to extremely small size, silver nanoparticles exhibit enhanced properties when compared with the bulk material. This includes those having large surface area relative to their volume, ability to easily interact with other particles and increased antibacterial efficiency.

The optical properties of colloidal silver particles require the application of Mie theory. If the diameter of the particles is $<20 \mathrm{~nm}$ the absorption in the UV range is only dependent on the dipole term in the Mie summation (Magudapathy et al 2001). Surface plasmon resonance (SPR) is a phenomenon occurring at silver surfaces, when an incident light beam strikes the surface at a particular angle. Depending on the thickness of a molecular layer at the metal surface, SPR results in a graded reduction in intensity of the reflected light. Size distribution of the particles leads to broadening or narrowing of plasmon bands with an absorption tail in the longer wavelengths.

Amongst the several methods that exist for synthesizing of nanoparticles the use of microwave assisted synthesis

*Author for correspondence (kjsreeram@clri.res.in) has shown promise (Komarneni et al 2002; Yamamoto et al 2004a, b; Tsuji et al 2004). In the case of silver nanoparticles, microwave assisted synthesis employing carboxymethyl cellulose sodium (CMS) as a reducing agent (Chen et al 2008) yielded silver nanoparticles, whose size was dependent on concentration of CMS and $\mathrm{AgNO}_{3}$. Preparation of silver nanoparticles and nanorods (Tsuji et al 2004; Navaladian et al 2008) in the presence of Pt seeds, polyvinyl pyrrolidine and ethylene glycol, has also been reported. Most of the methods reported in literature are based on non aqueous media and difficulties are encountered in the preparative steps. This work reports the use of starch as a template and reducing agent in the preparation of silver nanoparticles. The effect of synthetic strategy (uncontrolled/controlled heating and microwave synthesis) employed on the size and shape of the nanoparticles has been compared.

\section{Experimental}

\subsection{Reagents}

Silver nitrate and starch were purchased from Aldrich, USA and Merck India and were used without any purification. All the solutions were prepared in deionized water.

\subsection{Preparation of silver nanoparticles}

A $1 \%$ solution of starch was prepared. To this starch solution, silver nitrate $(5 \mathrm{mM})$ was added. The resultant solution was stirred for $30 \mathrm{~min}$. The transparent solution was taken for different methods of preparation of silver 
nanoparticles. In the first instance, an uncontrolled heating to a temperature of around $80^{\circ} \mathrm{C}$ was employed. In another experiment, the reaction mixture was subjected to controlled heating from $45-75^{\circ} \mathrm{C}$ over varying durations of time (rate of heating being $2^{\circ} \mathrm{C} / \mathrm{min}$ ). The reaction was also carried out under microwave irradiation, employing a domestic microwave oven. During preparation, the solution turned to the characteristic yellowish brown colour, then to grayish black, indicating the formation of silver nanoparticles. The silver nanoparticles thus prepared in starch using different methods were stable for two months without any change in the surface plasmon resonance as indicated from the absorption spectra at room temperatures, showing that the starch was a good reducing and stabilizing agent for the silver nanoparticles.

\subsection{Characterization methods}

The synthesized silver nanoparticles were characterized spectrophotometrically using Perkin Elmer UV-visible spectrometer. Particle size of the synthesized silver nanoparticles was analysed through photon correlation spectroscopy. Light scattering measurements were carried out at $90^{\circ}$ on a photon correlation spectrometer (PCS) Zetasizer 3000 HSA equipped with a digital autocorrelator from Malvern Instrument, UK. The transmission electron microscopy (TEM) micrographs, selected area electron diffraction (SAED) pattern and high resolution transmission electron micrographs (HRTEM) were taken for morphological analysis of nanoparticles with a JEOL 3010 field emission electron microscope with an accelerating voltage of $300 \mathrm{kV}$. The samples were analysed by preparing a dilute solution made in distilled water, drop casted on a carbon coated copper grid, followed by drying the sample at ambient conditions before it was attached to the sample holder on the microscope. The infrared (IR) spectrum was recorded on a Perkin Elmer RX-1 model FTIR spectrophotometer.

\section{Results and discussion}

\subsection{Formation of silver nanoparticles under uncontrolled heating}

A colourless clear solution appeared at room temperature which then turned into yellowish brown colour on heating for another $30 \mathrm{~min}$. With increasing duration of heat treatment, the colour gradually changed through yellowish brown to reddish brown and finally into grayish black. The temperature was found to be $80^{\circ} \mathrm{C}$ at the end of the reaction. Figure 1 shows the absorption spectra of starch stabilized silver nanoparticles taken at different time intervals (10-30 min) at $80^{\circ} \mathrm{C}$. From the spectra it can be observed that at room temperature, the reduction of $\mathrm{Ag}^{+}$ to $\mathrm{Ag}^{0}$ does not occur at room temperature, when starch was employed as reductant. As temperature increases the surface plasmon resonance typical of silver nanoparticles appears. The absorption maxima occurred at $420 \mathrm{~nm}$, indicating the formation of silver nanoparticles. The absorption maximum at $420 \mathrm{~nm}$ is attributed to the Mie scattering by silver metal (Aoki et al 2003). No change in absorbance was observed after a temperature of $80^{\circ} \mathrm{C}$ was attained, confirming the complete reduction of $\mathrm{Ag}^{+}$to $\mathrm{Ag}^{0}$. The number average diameter of the synthesized

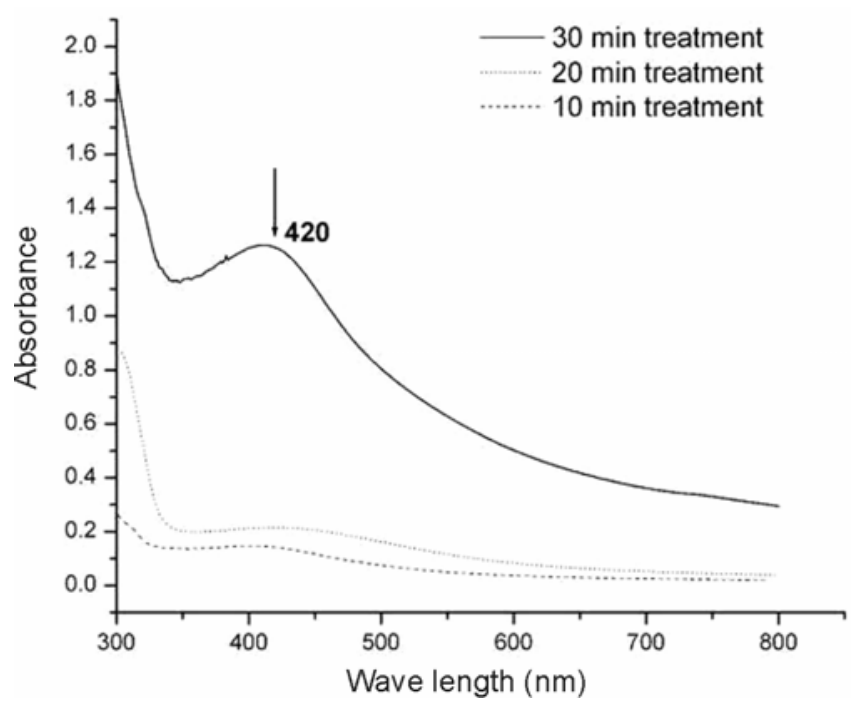

Figure 1. The UV-Visible absorption spectra of silver nanoparticles prepared by direct heating at $80^{\circ} \mathrm{C}$ for various durations.

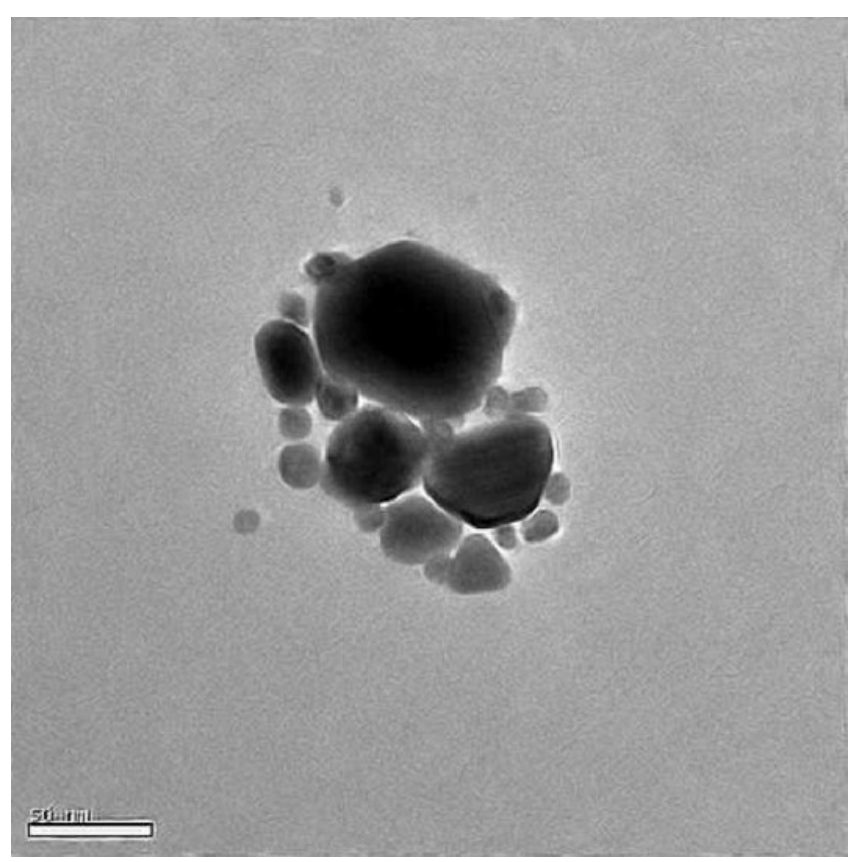

Figure 2. TEM image of silver nanoparticles of average diameter $30 \mathrm{~nm}$ prepared by direct heating at $80^{\circ} \mathrm{C}$ for $30 \mathrm{~min}$. 

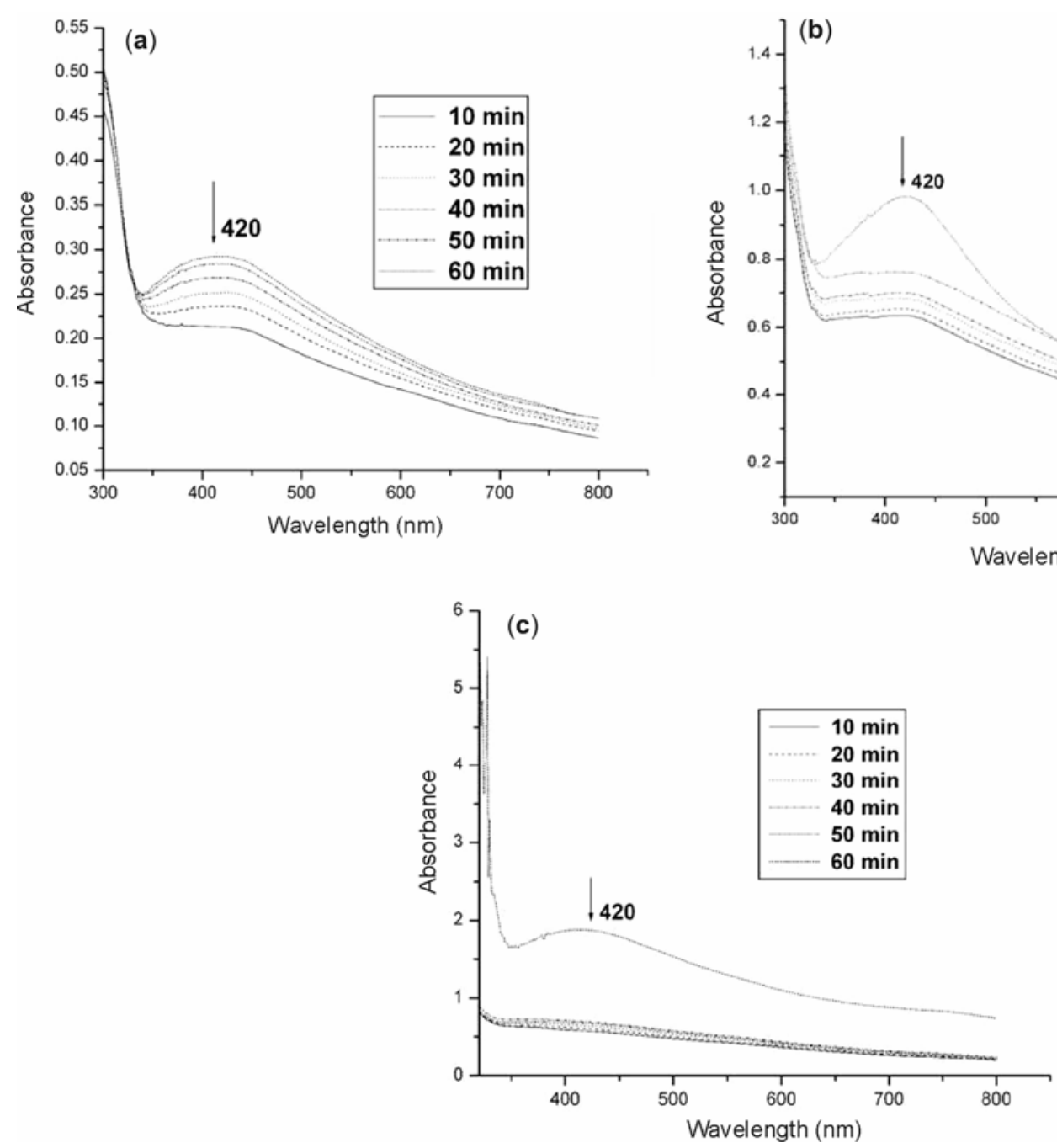

Figure 3. The absorption spectra of silver nanoparticles prepared under controlled heating at (a) $55^{\circ} \mathrm{C}$, (b) $65^{\circ} \mathrm{C}$ and (c) $75^{\circ} \mathrm{C}$.

Table 1. Particle size of silver nanoparticles synthesized under various conditions.

\begin{tabular}{lcc}
\hline Methods & $\begin{array}{r}\text { Hydrodynamic } \\
\text { diameter (nm) }\end{array}$ & $\begin{array}{c}\text { Number average } \\
\text { diameter (nm) }\end{array}$ \\
\hline Direct heating @ $90^{\circ} \mathrm{C}$ & 53 & 33 \\
Controlled heating @ $55^{\circ} \mathrm{C}$ & 45 & 28 \\
Controlled heating @ $65^{\circ} \mathrm{C}$ & 34 & 20 \\
Controlled heating @ $75^{\circ} \mathrm{C}$ & 39 & 26 \\
Microwave irradiation for 30 s & 55 & 17 \\
Microwave irradiation for $60 \mathrm{~s}$ & 46 & 10 \\
Microwave irradiation for $90 \mathrm{~s}$ & 45 & 8 \\
Microwave irradiation for $120 \mathrm{~s}$ & 42 & 7 \\
\hline
\end{tabular}

particles (table 1) was found to be around $33 \mathrm{~nm}$. Figure 2 presents the TEM images of silver nanoparticles synthesized under direct heating method. It can be seen that the particles are not uniform in size. Most of the particles exhibit a size of around $30 \mathrm{~nm}$, in confirmation with the photon correlation spectroscopy (PCS) measurements.

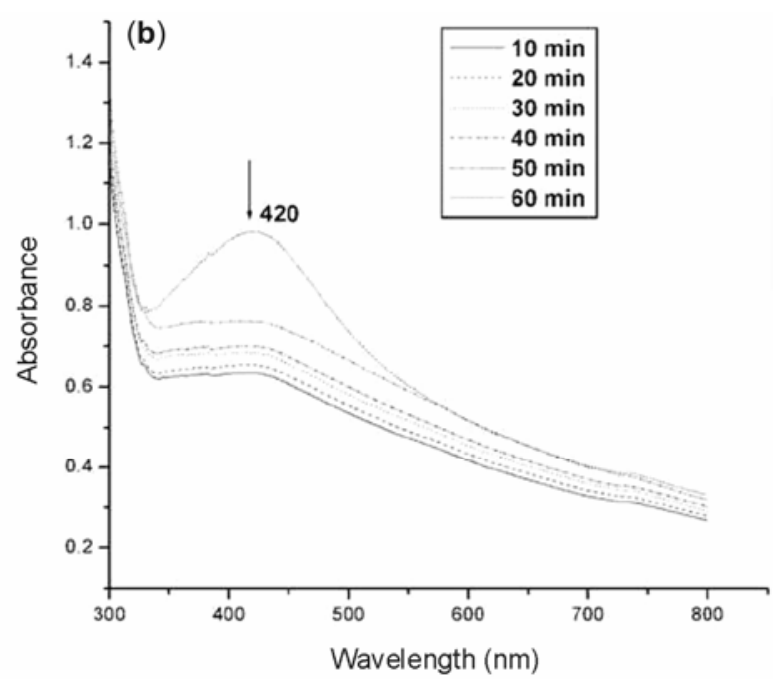

\subsection{Controlled heating}

The experiments were carried out from $45^{\circ} \mathrm{C}$ onwards and the variation in colour was noted at every $10^{\circ}$ rise in temperature. No change in colour of solution was monitored up to a temperature of $55^{\circ} \mathrm{C}$. Subsequently, the solution changes to yellow with increasing temperature. Figure 3 presents the changes in SPR spectra with temperature and time. The SPR at different temperatures are more or less similar. The particle size of silver nanoparticles synthesized at various temperatures is presented in table 1 . The size ranged from 20-30 nm. The TEM micrograph (figure 4) indicates that the controlled synthesis offers better control over particle size.

\subsection{Microwave irradiation}

The main advantages of microwave assisted methods over conventional synthetic methods are increase in the kinetics of reaction by two orders of magnitude, rapid initial 
heating and generation of localized heat at reaction sites, thereby increasing the rate of reaction (Liu et al 2005). The microwave assisted synthesis of silver nanoparticles was carried out by irradiating a mixture of silver nitrate and starch for 30-120 s. Figure 5 presents the absorption spectra under microwave irradiation. The change in particle size with duration of microwave irradiation is presented in table 1. Microwave irradiation provides for smaller particles, even at a shorter duration of treatment. TEM images clearly confirm that the silver nanoparticles formed under microwave irradiation have an average size of $12 \mathrm{~nm}$ (figure 6). The HRTEM image of single silver

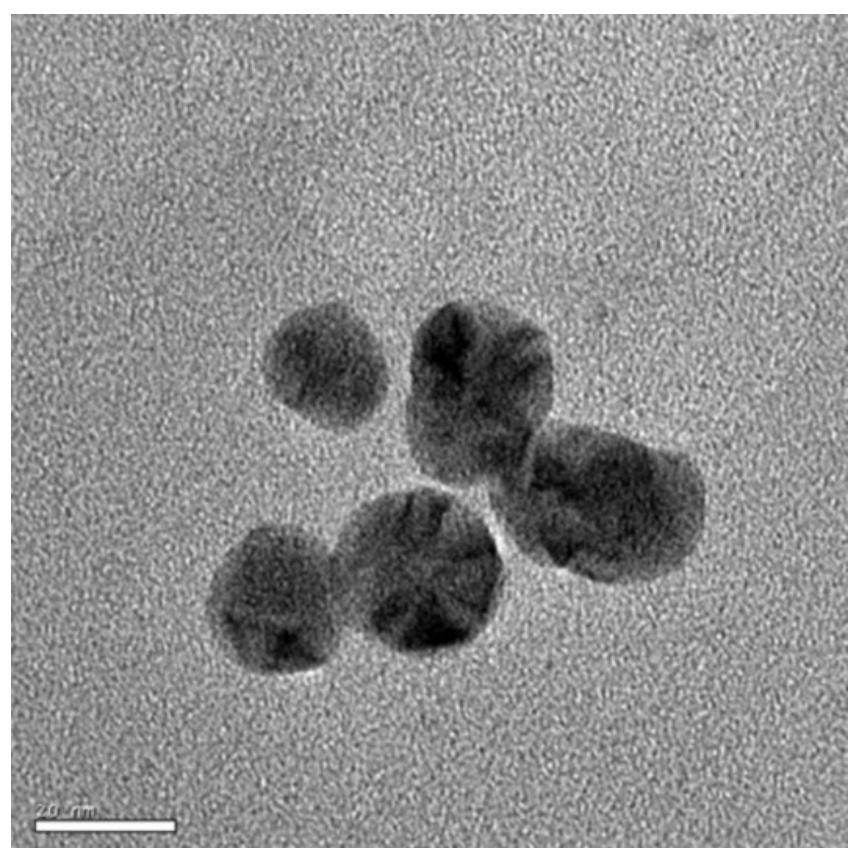

Figure 4. TEM image of silver nanoparticles synthesized through controlled heating at $75^{\circ} \mathrm{C}$.

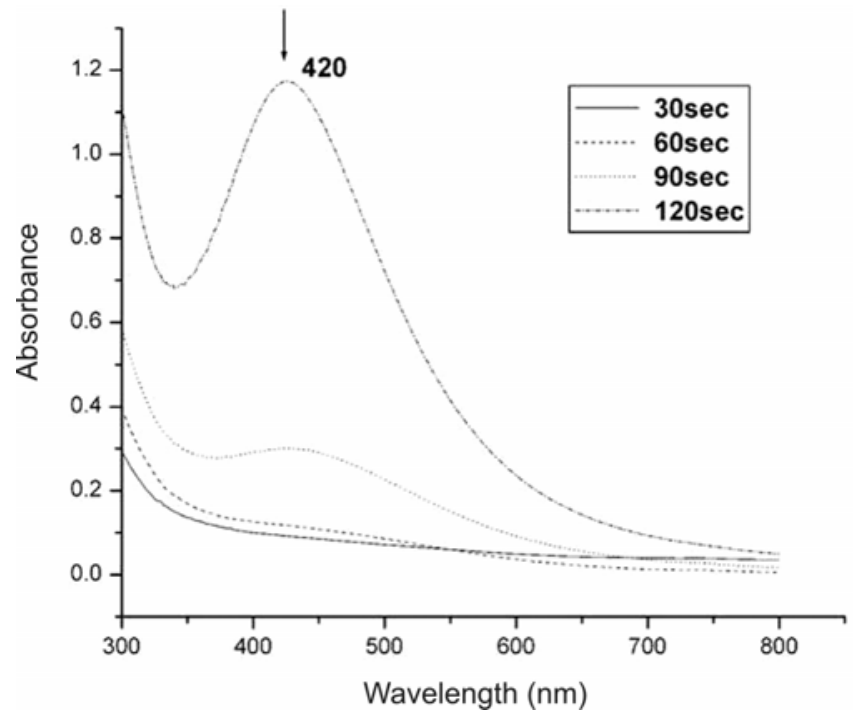

Figure 5. The absorption spectra of starch stabilized silver nanoparticles synthesized under microwave irradiation. nanoparticles is presented in figure 7. HRTEM clearly shows the spherical morphology of nanoparticles. From the SAED pattern (figure 8), the silver nanoparticles appear to be twinned. Compared to other methods the formation of silver nanoparticles is faster. The number of hydroxyl groups in starch can help the reduction of silver ions. The nanoparticles could have grown through reduction of silver ions inside the nanoscopic starch templates, with the

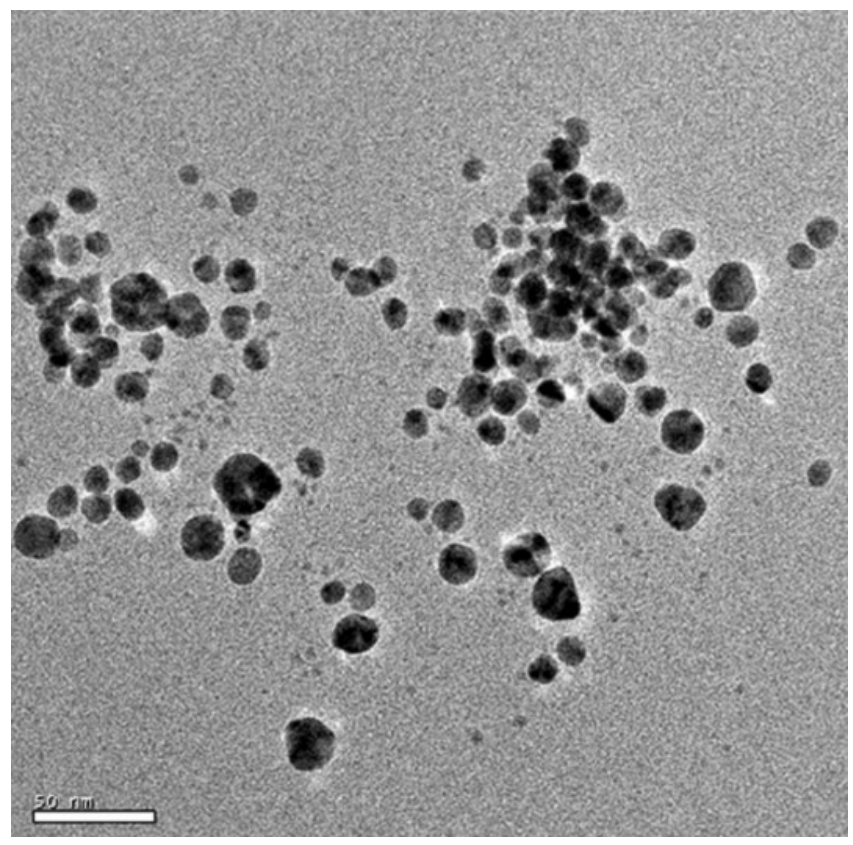

Figure 6. TEM image of the starch stabilized silver nanoparticles with an average diameter of $12 \mathrm{~nm}$ using microwave irradiation method.

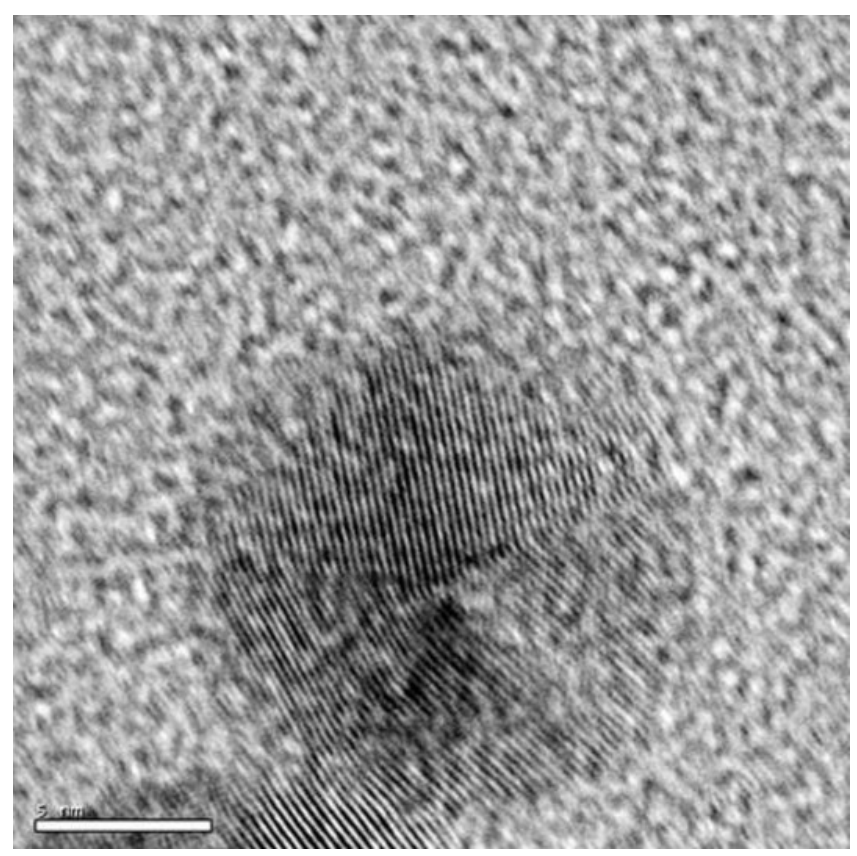

Figure 7. HRTEM image of a single silver nanoparticles prepared under microwave irradiation. 
starch's hydroxyl groups acting as passivation contacts for the stabilization of the nanoparticles, similar to the observation of Lu et al (2005) in the case of tellurium nanowires. Starch is also renewable, soluble in water and binds to the nanoparticles relatively weakly so that the protection should be easily reversible at higher temperatures. The non-aggregation of the particles even at higher durations of heating at different methods of synthesis as indicated from the particle size measurements further confirms that starch serves both as a reducing agent and stabilizer of the silver nanoparticles. The infrared spectra of the dried nanoparticles of silver using starch as a template and employing microwave synthesis along with that of starch is presented in figure 9. An extremely broad

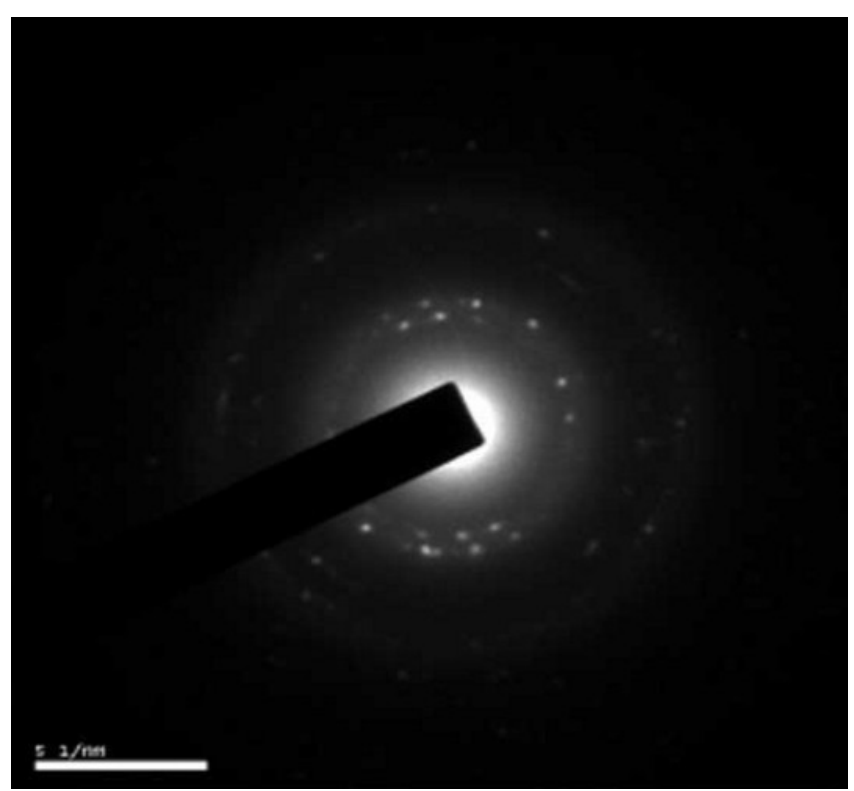

Figure 8. SAED pattern of the nanoparticles.

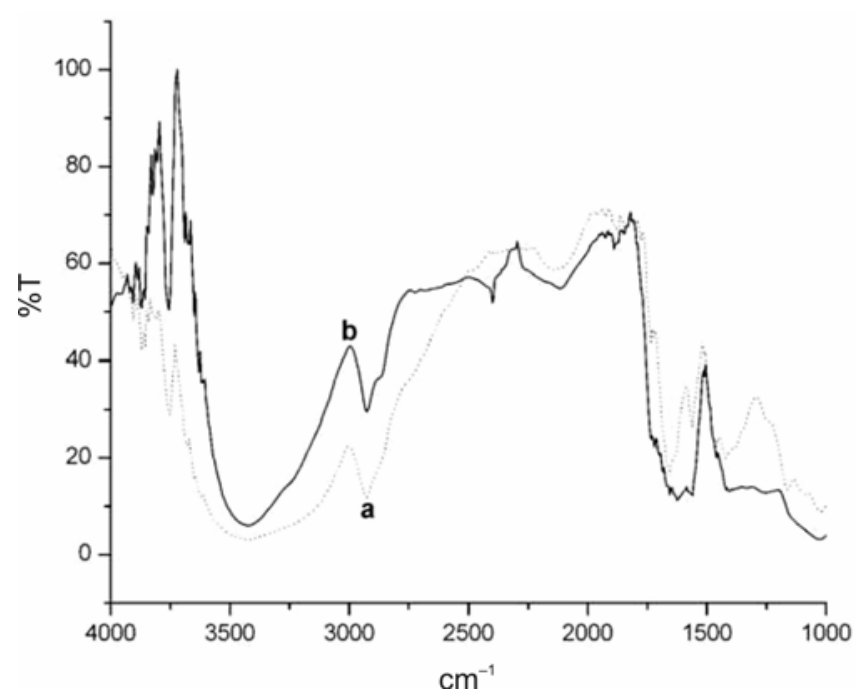

Figure 9. Infrared spectra of (a) reducing agent (starch) and (b) obtained nanoparticles of silver. band due to hydrogen bonded hydroxyl groups $(\mathrm{O}-\mathrm{H})$ appears at around $3425 \mathrm{~cm}^{-1}$ for starch, which narrows down to $3426 \mathrm{~cm}^{-1}$ band in the case of silver nanoparticles. It can be found that the IR spectra of silver nanoparticles as well as that of starch are more or less similar. Some minor changes in the fingerprint region of starch such as the peaks at 1083 and $1022 \mathrm{~cm}^{-1}$ attributable to the anhydroglucose ring $\mathrm{O}-\mathrm{C}$ stretch in the case of starch appears to be broad in the case of silver, indicating a possible coating of the silver nanoparticles with starch. Absence of a band at $1384 \mathrm{~cm}^{-1}$ indicates the complete reduction of $\mathrm{Ag}^{+}$to $\mathrm{Ag}^{0}$.

The synthesis utilizes only non-toxic materials and water as solvent, and has a potential for industrial application on account of the lower time taken for the reduction.

Most critical of any nanoparticles synthesis strategy is the particle size distribution. Figure 10 presents the particle size distribution pattern of the synthesized nanoparticles under direct heating at $80^{\circ} \mathrm{C}$, controlled heating at $80^{\circ} \mathrm{C}$ and microwave irradiation. It can be observed that the microwave synthesis provides for a high monodisperse character with the particle size minima and maxima lying between 5-15 $\mathrm{nm}$ as against $10-40$ and $20-60 \mathrm{~nm}$ for controlled and direct heating, respectively. The ability of microwave irradiation to bring about reduction of $\mathrm{Ag}^{+}$to $\mathrm{Ag}^{0}$ within $120 \mathrm{~s}$ as against a minimum of $60 \mathrm{~min}$ for other methods is an indication of the superiority of the method. The template method provides good control over the shape and dimensions of nanoparticles and is faster under the microwave irradiation method. The microwave irradiation effectively utilizes the internal heat generated within the matrix and is able to bring about the complete reduction within shorter duration of time.

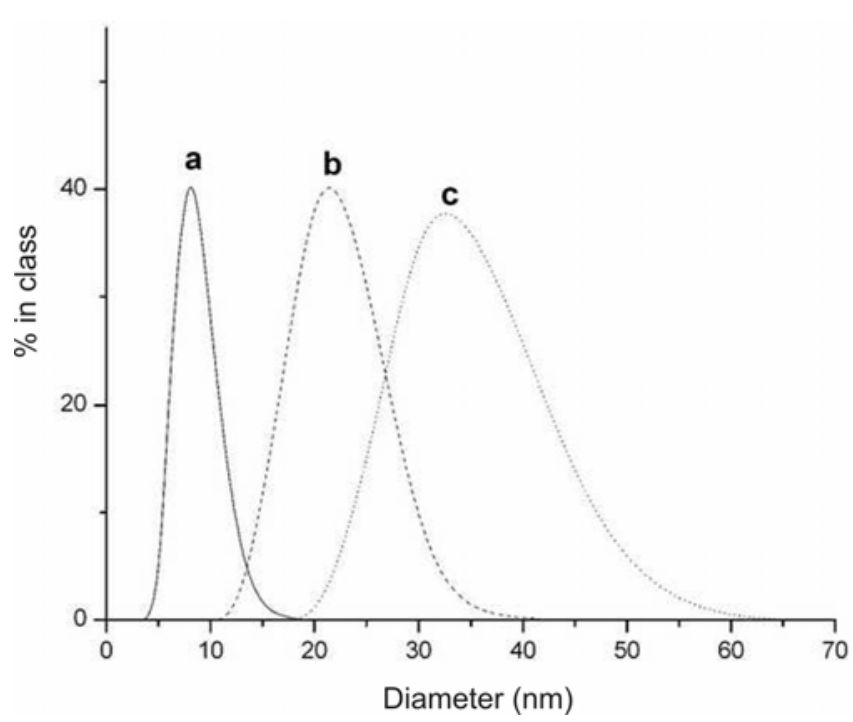

Figure 10. Particle size distribution plot for silver nanoparticles prepared by (a) microwave irradiation, (b) controlled heating at $75^{\circ} \mathrm{C}$ and (c) direct heating at $80^{\circ} \mathrm{C}$. 


\section{Conclusions}

Synthesis of silver nanoparticles from silver nitrate employing starch as the reductant cum stabilizing agent has been carried out under direct heating, controlled heating and microwave irradiation. Starch acts as a reductant as well as a capping material to protect the nanoparticles surfaces and prevents the particles from aggregation. It provides efficient, simple and good control over the particle. While very high temperatures were required to carry out the reduction, the same was possible within seconds under microwave irradiation. Absorption spectra confirm the presence of surface plasmon resonance at $420 \mathrm{~nm}$, characteristic of $\mathrm{Ag}$ nanoparticles. Compared to other methods investigated in this study the microwave irradiation was considered as better for reduction of silver ions to silver nanoparticles. It also afforded smaller particle sizes and particle size distribution. The pure silver nanoparticles produced in this manner, therefore, are potentially suitable for medical or biological applications, enabled by the non-toxic stabilizing agents demonstrated in this work.

\section{Acknowledgement}

The authors thank CSIR for the funding received under the CSIR Young Scientist Project.

\section{References}

Aoki K, Chen J, Yang N and Nagasava H 2003 Langmuir 19 9904

Chen J, Wang J, Zhang X and Jin Y 2008 Mater. Chem. Phys. 108421

Elenchiguerra J L, Burt J L, Morones J R, Camacho-Bragado A, Gao X, Lara H H and Yacaman M J 2005 J. Nanobiotech. 36

Evanoff D D and Chumanov G 2005 Chem. Phys. Chem. 6 1221

Kelly K L, Coronado E, Zhao L L and Schatz G C $2003 \mathrm{~J}$. Phys. Chem. B107 668

Komarneni S, Li D S, Newalker B, Katsuki H and Bhalla A S 2002 Langmuir 185959

Liu F -K, Huang P -W, Chu T -C and Ko F -H 2005 Mater. Lett. 59940

Lu Q, Gao F and Komarneni S 2005 Langmuir 216002

Magudapathy P, Gangopadhyay P, Panigrahi B K, Nair K G M and Dhara S 2001 Physica B299 142

Navaladian S, Viswanathan B, Varadarajan T K and Viswanath R P 2008 Nanotechnology 1945603

Pal A and Pal T 1999 J. Raman Spectrosc. 30199

Tsuji M L, Nizhizawa Y, Hashimoto M and Tsuji T 2004 Chem. Lett. 33370

Yamamoto T, Yin H B, Wada Y, Kitamura T, Sakata T, Mori H and Yanagida S 2004a Bull. Chem. Soc. Jpn 77757

Yamamoto T, Wada Y, Sakata T, Mori H, Goto M, Hibino S and Yanagida S 2004b Chem. Lett. 33158 